\title{
The Role of Latero-Frontal Cirri in Particle Capture by the Gills of Mytilus edulis
}

\author{
HAROLD SILVERMAN ${ }^{1}$, JOHN W. LYNN, PETER G. BENINGER*, AND THOMAS H. DIETZ \\ Department of Biological Sciences, Louisiana State University, Baton Rouge, Louisiana 70803; and \\ * Département de Biologie, Faculté des Sciences, Université de Nantes, 2 rue de la Houssinière. \\ 44322 Nantes Cedex, France
}

\begin{abstract}
In this study we examined the mechanism of particle capture in Mytilus edulis, using radioactive-label clearance studies, progressive fixation, and scanning electron microscopy to visualize in detail the cirri and their range of motion. Confocal laser scanning microscopy was used to observe the interaction of cirri with $1 \mu \mathrm{m}$ fluorescent latex particles on live strips of control and serotonintreated isolated gill tissue. The gills of $M$. edulis possess large, complex latero-frontal cirri composed of 18-26 pairs of cilia. Particles that were intercepted by the cirri were transferred to the water current on the frontal surface of the filament where they were propelled toward the ventral particle groove. Clearance studies demonstrated that $M$. edulis removed Escherichia coli from $5^{\circ} \mathrm{C}$ seawater bathing medium at $4.9 \mathrm{ml} \mathrm{g}^{-1}$ dry tissue $\mathrm{min}^{-1}$. When the gills were exposed to $10^{-3} M$ serotonin, the latero-frontal cirri stopped moving and became fixed in a flexed position that partially blocked the frontal surface of the filament. Clearance studies demonstrated that removal of $E$. coli from the seawater bathing medium was reduced $90 \%$ to $0.5 \mathrm{ml} \mathrm{g}^{-1}$ dry tissue $\min ^{-1}$ when $10^{-3} M$ serotonin was present. These data demonstrated that for small particles $(<2 \mu \mathrm{m})$ in the near field, movement of cirri was essential for successful capture either by direct contact or with water acting as a hydromechanical coupler.
\end{abstract}

\section{Introduction}

Considerable progress in understanding particle processing mechanisms in suspension-feeding bivalves has been made in recent years (Beninger et al., 1993, 1997; Jørgensen, 1990; Ward et al., 1998b). Investigations have focused on various components of the feeding sequence:

Received 3 June 1999; accepted 5 October 1999.

${ }^{1}$ To whom correspondence should be addressed. E-mail: cxsilv@lsu.edu capture-transport-selection-ingestion. However, the actual mechanism(s) of particle capture remains difficult to determine.

A number of components are important in understanding the mechanism of particle capture. Fluid mechanics has been used to describe both the delivery of particles to the gill filaments and their movement on the gill (Jørgensen, 1983; Nielsen et al., 1993; Ward et al., 1998a; Riisgård and Larsen, 2000). The potential interaction of particles with a structure on the gill would be an equally important component to understanding the mechanisms leading to particle capture events. Generally, suspension feeding bivalves can capture particles over a wide range of sizes from $10^{-1} \mu \mathrm{m}$ to $10^{2} \mu \mathrm{m}$, with most showing efficient clearance of particles in the range of a few to tens of $\mu \mathrm{m}$ (Møhlenberg and Riisgård, 1978; Ten Winkel and Davids, 1982; Sprung and Rose, 1988). The mechanisms used to capture particles at the extremes of the size range may differ, because the behavior in fluid would change depending on particle density and geometry.

To observe the actual particle capture event, one needs to be able to resolve both the particle and the cellular organelles that are involved with the capture. To date, Riisgård and his colleagues have used isolated preparations and constructed half filament models to analyze particle movements close to the filaments of Mytilus edulis (Nielsen et al., 1993; Riisgård et al., 1996). Their observations indicate that particles can be directed to the frontal surface of gill filaments by direct interception of particles by latero-frontal cirri. They have extended these observations by determining the path as particles approach the gill filaments, in vivo, using a side-mounted microscopic preparation (Riisgård and Larsen, 2000).

Silverman et al., (1996, 2000) and Beninger et al., (1997) have examined gill strips using confocal laser scanning 
microscopy (CLSM). The disadvantages of this system are that the observations are made on gill strips that are isolated; normal fluid flow is altered; and normal neural or hormonal cues are modified or missing. However, the advantages of this system include magnification, resolution, tunable depth of focus, and preselection of a gill strip where all cilia are in motion as confirmed by observation before adding particles. The near-field events of particle interaction with cirri are not altered by isolation procedures. The only bivalve investigated to date using this technique is Dreissena polymorpha, a species with a homorhabdic eulamellibranch gill type (Silverman et al., 1996). In this freshwater bivalve, the latero-frontal cirri direct particles from the water onto the frontal surface of the gill filaments, where the particles were transported to the ventral particle groove by the frontal cilia.

Mytilus edulis, a marine bivalve species often used for a variety of particle capture studies, has a homorhabdic filibranch gill type. It also has latero-frontal cirri and a ventral particle groove (Atkins, 1937; Owen, 1974; Owen and McCrae, 1976). The organization and structure of laterofrontal cirri in $M$. edulis have been extensively described (Moore, 1971; Owen, 1974; Owen and McCrae, 1976; Jones et al., 1990). The cirri are large, complex structures composed of two ciliary plates; each plate consists of between 18 and 26 fused cilia that are hinged at the base (Owen, 1974). The tips of the cilia are free and oriented at an angle, suggesting a "paddle" or "filtering" structure (Riisgård et al., 1996). Capture and retention studies have shown that $M$. edulis can intercept particles down to $1 \mu \mathrm{m}$ with retention efficiencies of approximately $50 \%$ (Møhlenberg and Riisgård, 1978). Using a video microscope to observe single isolated gill filaments, Riisgård et al., (1996) showed that the latero-frontal cirri of $M$. edulis can intercept relatively large $(7 \mu \mathrm{m})$ particles. However, the exact sequence of particle-cirrus interaction was not readily resolvable.

In the present study we examined small particle capture by live gill strips using confocal microscopy and high-speed video recording. This approach enabled us to document in detail particle-cirrus interactions in the marine bivalve, Mytilus edulis. We reported some of the preliminary data recently in a brief commentary (Silverman et al., 2000).

\section{Material and Methods}

\section{Animals}

Observations were made on Mytilus edulis individuals collected at low tide in Chamcook Harbour (Passamaquoddy Bay, Bay of Fundy, Canada) and on animals purchased from the Marine Biological Laboratory (Woods Hole, Massachusetts). The specimens were flown on moist icepacks to the Life Sciences Microscopy Facility at Louisiana State University. Specimens from Canada were stored for 1-2 days at $4^{\circ} \mathrm{C}$ in seawater-soaked towels prior to dissection and observation. Specimens from Woods Hole were maintained in the laboratory for several months in artificial seawater (Chambers and de Armendi, 1979) at $4^{\circ}-6^{\circ} \mathrm{C}$ and fed algae weekly until used.

\section{Confocal laser scanning microscopy}

In larger specimens $(\geq 30 \mathrm{~mm}$ anterior-posterior shell length), the posterior extremity of the gill was used for CLSM preparations, because the demibranchs are thinnest and shortest in this region, while still presenting the typical gill architecture. This preparation facilitated the observation of 4-5 mm wide strips of gill extending from the gill arch to the ventral particle groove. Strips from the posterior extremity of each demibranch were removed using microsurgical instruments, and placed in isosmotic (1060 mosm) seawater on a microscope slide lined with Nitex screen (125 $\mu \mathrm{m}$ mesh). This screen allowed cilia-generated water currents to flow on both sides of the demibranch, and mechanical disturbance of the gill was avoided by supporting the coverslip above the preparation with silicone vacuum lubricant posts at each corner. For larger animals with thicker gills, we also observed single isolated filaments. For specimens $<30 \mathrm{~mm}$, the gill was sufficiently small and thin to allow any region to be used. We observed the gills of more than 40 specimens (range of shell length $=18-81 \mathrm{~mm}$ ) during this study.

The preparations were observed using the CLSM technique previously described (Silverman et al., 1996). The gills were examined with a Noran Instruments confocal system attached to a Nikon Optiphot microscope with a $40 \times$ fluor lens (NA 1.3). The laser wavelength was set at $529 \mathrm{~nm}$ with an FITC barrier filter in the return image path. Reflected channel images were acquired (laser scan and image digitization $<1 \mu \mathrm{s} /$ frame) and sequentially stored at 120 frames $\mathrm{s}^{-1}$ ( $\sim 8 \mathrm{~ms}$ between frames). Images were captured and analyzed using the Odyssey InterVision (Noran) software on a Silicon Graphics Indy computer. Images were not altered except to adjust the contrast.

Fluorescent beads of $0.7 \mu \mathrm{m}$ or $1.0 \mu \mathrm{m}$ diameter were added to the preparations to track particle motion in ciliagenerated water currents and particle transport on the ciliated epithelia. Gill preparations were oriented such that beads could be added under the coverslip in the dorsal region of the strip and subsequently moved from dorsal to ventral. Particle velocities were determined after observing the movement of individual fluorescent beads over known distances and times.

\section{Scanning electron microscopy}

To examine the spatial relationships of cirri and cilia, gill tissue was prepared for scanning electron microscopy using a progressive fixation technique that allowed the arrest of cilia at all stages of their beat cycles. Small mussels were placed in containers with enough seawater $(\sim 20-30 \mathrm{ml})$ to cover the shells. They were left undisturbed until their 
siphons were clearly visible. Drops of $2 \% \mathrm{OsO}_{4}(1-2 \mathrm{ml})$ were slowly added near the edge of the container; the specimen was left intact for $20 \mathrm{~min}$. The posterior adductor muscle was then cut and the animal exposed to fixative for another $40 \mathrm{~min}$. In a few cases, the adductor muscle was carefully cut before $\mathrm{OsO}_{4}$, was added, with total exposure to osmium in the bath being $30 \mathrm{~min}$. The mussels were then rinsed in seawater and fixed for an hour in $2 \%$ glutaraldehyde in seawater. After fixation, the gill was removed, dehydrated in a graded ethanol series, critical-point dried, and sputter-coated with gold-palladium. Specimens were mounted on stubs and visualized with a Cambridge Scanning Electron Microscope. Some gills were removed and photographed before and after fixation, and again after critical-point drying to monitor tissue shrinkage.

\section{Bacterial clearance}

Clearance of ${ }^{35} \mathrm{~S}$-labeled Escherichia coli from the bathing medium was quantified with an adaptation of the method of Riisgård (1988) as described previously (Silverman et al., 1995, 1997). Mussels (<30 mm shell length) were placed in individual test tubes containing $20 \mathrm{ml}$ aerated artificial seawater $\left(5^{\circ} \mathrm{C}\right)$ with or without $10^{-3} \mathrm{M}$ serotonin for $15 \mathrm{~min}$. Radiolabeled bacteria were added to each tube after the mussels opened their siphons, and after $1 \mathrm{~min}$ equilibration, four samples $(100 \mu \mathrm{l})$ were collected at 10 min intervals. The reduction of bathing medium radioactivity followed first order kinetics, and the clearance was expressed as $\mathrm{ml} \mathrm{g}^{-1}$ dry tissue $\mathrm{min}^{-1}$. Data are expressed as the mean \pm one standard error with the number of animals in parentheses.

\section{Results}

\section{Cirral structure}

Progressive fixation stopped the cirri and cilia in various stages of their beat cycle. The cirri position varied from being arched over the frontal surface of a gill filament to extending into the interfilament space (Fig. 1). Adjacent cirri on a filament were arrested during fixation in a staggered pattern, such that neighboring cirri were not in the same position relative to the frontal surface (Fig. 1). The CLSM time series micrographs (Figs. 3-6) are of filaments in the same orientation as in Figure 1. Confocal images of a cirrus beat cycle indicated that during the power stroke the cirrus bent over the frontal surface into a flexed position (Fig. 2D). On recovery it returned to an extended position perpendicular to the apical surface of the latero-frontal cirrus cell (Fig. 2A, I). The body of the cirrus beat as a single unit; a complete beat required the cirral body to pivot at its base in addition to moving through the ciliary waveform (Fig. 2). The cirrus moved out of the plane of focus during the flexion, but as the free ciliary tips were moving out of view they were clearly resolvable (Fig. 2E). The high

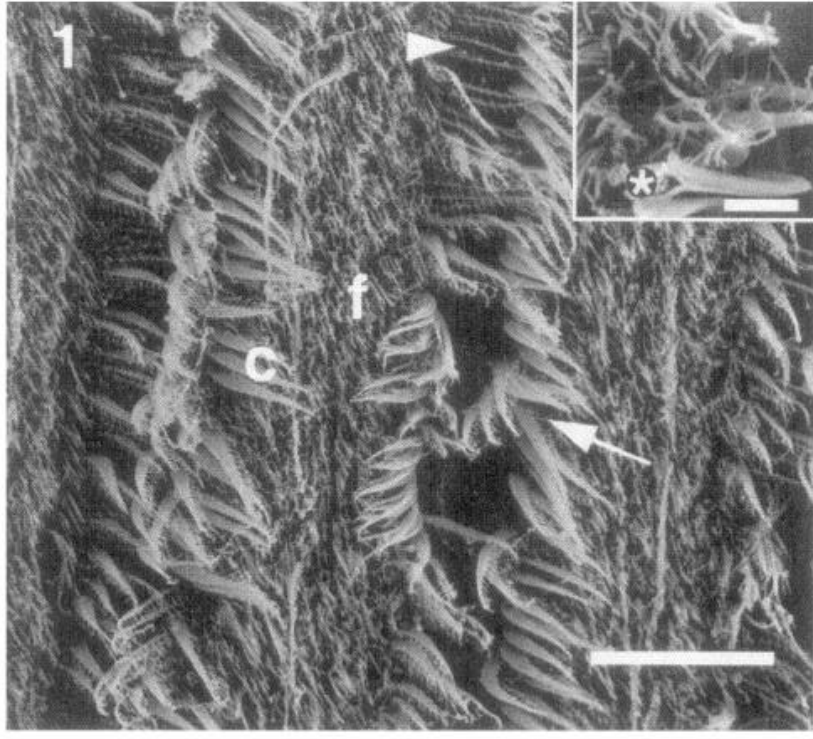

Figure 1. Scanning electron micrograph of gill filaments from Mytilus edulis treated to allow fixation of cirri during the beat cycle. Cirri flex during their power stroke moving over the frontal surface (f) of the filament. Cirri are in the extended position (arrowhead) in the interfilament space, and in the flexed position (c) with their free tips bent over the frontal surface. Adjacent cirri on a filament were stopped at different stages of a beat cycle (arrow). The inset of a higher magnification indicates that the free ciliary tips associated with the two ciliary plates of a cirrus angle away from the body of the cirrus to give a ' $V$ ' like appearance (*). Bar $=25 \mu \mathrm{m}$; inset $\mathrm{bar}=5 \mu \mathrm{m}$.

rate of capture of each image $(<1 \mu \mathrm{s})$ minimized blurring due to the movement of the cirrus (Fig. 2E). The cirral beat averaged $7.9 \pm 0.4 \mathrm{~Hz}(n=6)$.

\section{Cirral interaction with particles}

Particles interacted with moving cirri in several different ways but usually were (i) swept onto the frontal surface of the filaments and entrained into the frontal water current (Fig. 3). Fluorescent particles $(1 \mu \mathrm{m})$ entering the interfilament space were captured within the $2.2-2.8 \mu \mathrm{m}$ wide "V" of the free ciliary tips of the cirrus and moved toward the frontal surface as the cirrus beat from the extended into the flexed position. In most cases, particles interacting with a cirrus were moved directly into the frontal current and transported at $307 \pm 36 \mu \mathrm{m} \mathrm{s}^{-1}, n=4$ (Figs. 3, 4) toward the ventral particle groove.

Three additional types of particle interaction with a beating cirrus were observed. (ii) During flexion of the cirrus the particle may be deposited at the edge of the frontal surface without being immediately transported. Subsequent cirral movement positioned the particle into the frontal surface current (Fig. 4). (iii) Some particles remained between the cirral plates and moved with the cirrus for multiple beat cycles (Fig. 5). These particles were finally incorporated into the frontal flow after several cirral beat cycles. The particles that moved with the cirral extension away from the 

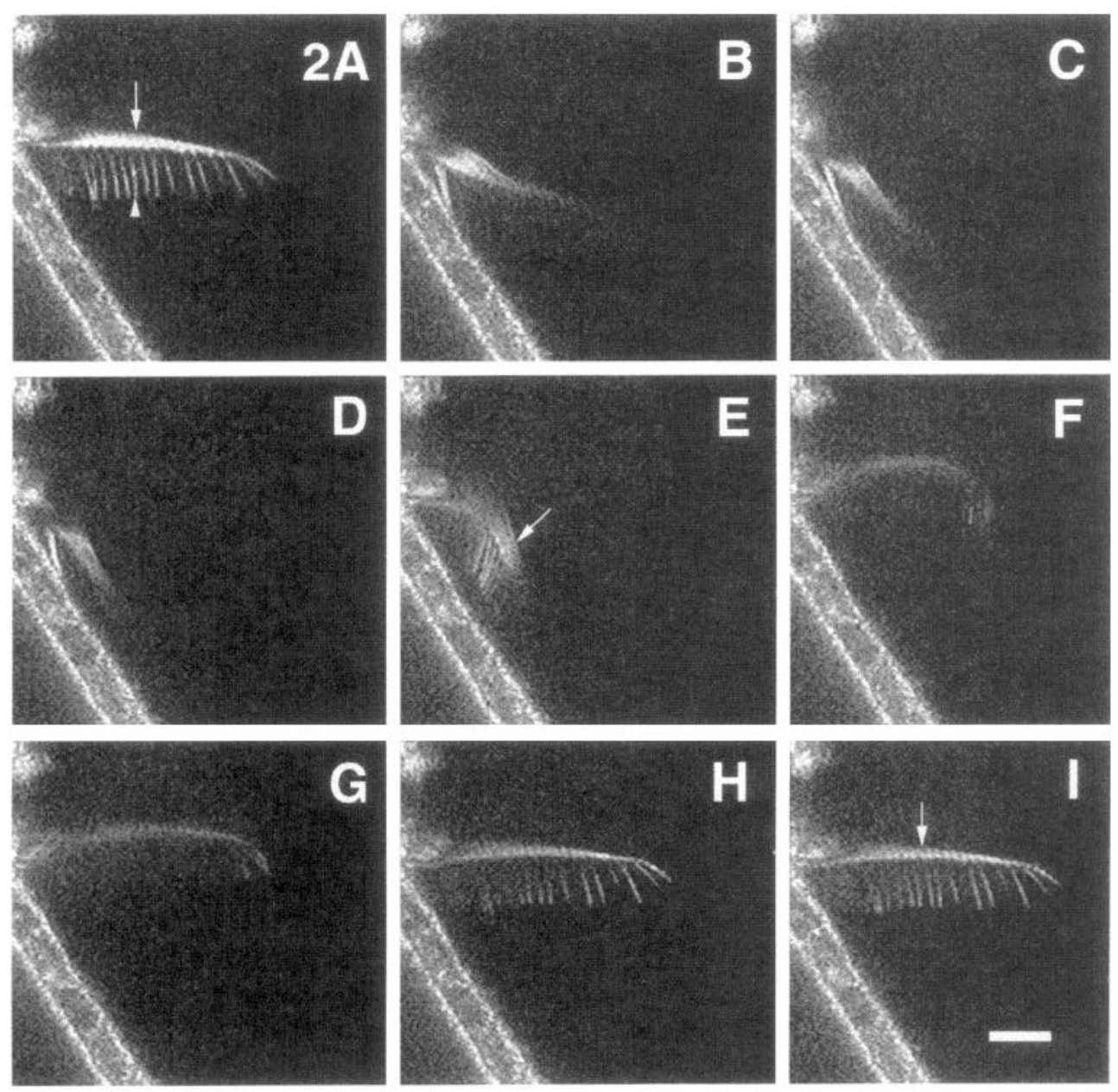

Figure 2. A series of confocal video images ( 120 frames $\left.\mathrm{s}^{-1}\right)$ of a single cirrus from an in vitro gill strip of Mytilus edulis. The time between each frame shown in this series is $25 \mathrm{~ms}$. The focal plane of the video is slightly off the perpendicular to the dorso-ventral axis of the filament. The parallel bright lines flank the lateral surface of the filament. Thus, the beat of the cirral tip is toward the frontal surface of the filament that lies to the right and into the background, at a right angle to the visible lateral surface of the filament. The resolution of individual ciliary tips (arrowhead) on one side of the cirrus (one cirral plate) is clear. The bending (power stroke) in A-D moves the plane of the ciliary tips toward the frontal surface of the filament. Images in frames E-I represent the recovery stroke. The total time taken for this beat cycle was $\sim 200 \mathrm{~ms}$ (beat frequency $\sim 5 \mathrm{~Hz}$ ). The arrow identifies the midpoint of the cirrus. Bar $=4 \mu \mathrm{m}$.

frontal surface suggest that there was intimate contact, either directly or within a few tenths of a $\mu \mathrm{m}$, from a cirrus (Fig. 5). (iv) Finally, on rare occasions the particle did not reappear, indicating it became dislodged from the cirrus in the interfilament space (not shown).

Particle entrainment in the frontal surface current of the gill was observed both in association with mucus rafts (Beninger $e t$ al., 1993, 1997) and in the absence of any visible mucus rafts (Figs. 3, 4). Indeed, we have observed filaments where two particles were being transported, but at different velocities. One moving particle can overtake another particle on the frontal surface (Fig. 6). Such events indicate independent transport of the two particles along the frontal surface, and would suggest that they were not moving in a single mucus raft, or not at the same height above the epithelium. Quick-time videos used to construct Figures 3-6 are archived in the electronic data base of The Biological Bulletin at www.mbl.edu/html/BB/ VIDEO/BB.video.html.

\section{Serotonin effects on cirral position and clearance of Escherichia coli}

Progressive fixation (as described above) revealed that the cirri in the serotonin-treated animals were arrested in the flexed position, occluding most of the frontal surfaces of the gill filament (Fig. 7). The amount of frontal surface covered by the cirri is somewhat exaggerated in this figure because the fixation caused $44 \pm 3 \%(n=4)$ shrinkage. From our CLSM observations in some sections of the gill, both frontal and lateral cilia continued to beat in the presence of $10^{-3} \mathrm{M}$ 

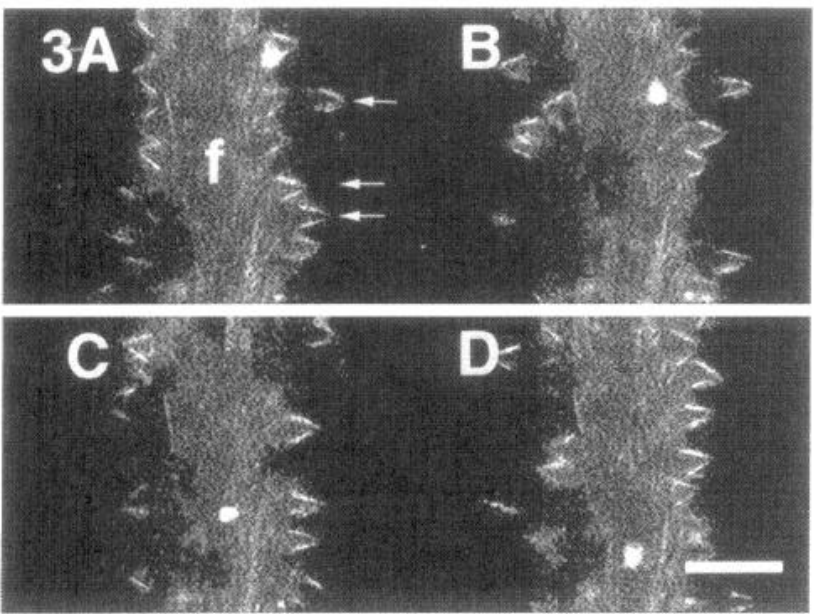

Figure 3. A confocal microscopy time series of the frontal surface of an in vitro gill filament from Mytilus edulis. Dorsal is at the top of each image and ventral toward the bottom. The time elapsed between each successive frame is $33 \mathrm{~ms}$. Cirral tips are visible as ' $\mathrm{V}$ ' structures (arrows). The cirri beat in and out of the plane of the image and the ' $\mathrm{V}$ 's are the tips of the cirri as they flex over the frontal surface on each side of the filament. One cirrus directed a $1-\mu \mathrm{m}$ fluorescent latex particle onto the edge of the filament from the right interfilament space (A; bright spot at top right). The particle was entrained in the frontal water current and moved ventrally down the frontal surface (B). The particle was transported on the frontal surface of the filament (C and D) moving $20 \mu \mathrm{m}$ in $100 \mathrm{~ms}$ by frame $\mathrm{D}$. Bar $=10 \mu \mathrm{m}$.

serotonin. This was also evident in some areas of gill that were fixed for scanning microscopy. This motion is inferred in the wave-like pattern formed by the tips of lateral cilia (Fig. 7). Although the fixation was not instantaneous, the positions of the lateral cilia tips are suggestive of a synchronized or metachronal motion (Fig. 7).
To assess particle capture in the absence of movement by latero-frontal cirri, cirral motion was arrested by adding $10^{-3} M$ serotonin to the seawater bathing medium (Jørgensen, 1983; Ward et al., 1998a). Clearance $\left(\mathrm{ml} \mathrm{g}^{-1}\right.$ dry tissue $\left.\min ^{-1}\right)$ of ${ }^{35} \mathrm{~S}$-labeled $E$. coli by $M$. edulis in $5^{\circ} \mathrm{C}$ seawater was $4.92 \pm 0.43(n=3)$ for controls $(130 \pm 12$ mg dry tissue) compared to $0.51 \pm 0.18(n=3)$ for treated animals (142 $\pm 26 \mathrm{mg}$ dry tissue). Clearance of bacteria from control mussels displayed first order kinetics with 21 min required to remove $50 \%$ of the label (Fig. 8). The serotonin-treated mussels also displayed first order kinetics, but experienced an $89.6 \%$ reduction in the rate of removal of bacteria from the seawater.

\section{Discussion}

The movement of an individual cirrus on a living strip of Mytilus edulis gill can be observed at high resolution using confocal laser scanning microscopy (CLSM). The beat cycle is similar to that described for the cirri of Dreissena polymorpha (Silverman et al., 1996). In the flexed position the tips of the cirri are located over the frontal surface of the gill filament, whereas in the extended position they project into the interfilament space at the level of the latero-frontal cells from which they originate.

Confocal microscopy permits resolution of individual cirri and, depending on reflectance and light scattering, includes their individual ciliary tips. The lateral $(x-y$ plane $)$ resolution (about $0.2 \mu \mathrm{m}$ ) of CLSM, the enhanced rate of sequential image acquisition ( $\sim 8 \mathrm{~ms} /$ frame), and high speed of capture of individual images $(<1 \mu \mathrm{s})$ enabled observation of the interaction of $1-\mu \mathrm{m}$ particles with laterofrontal cirri. Although particles were seen to be directed
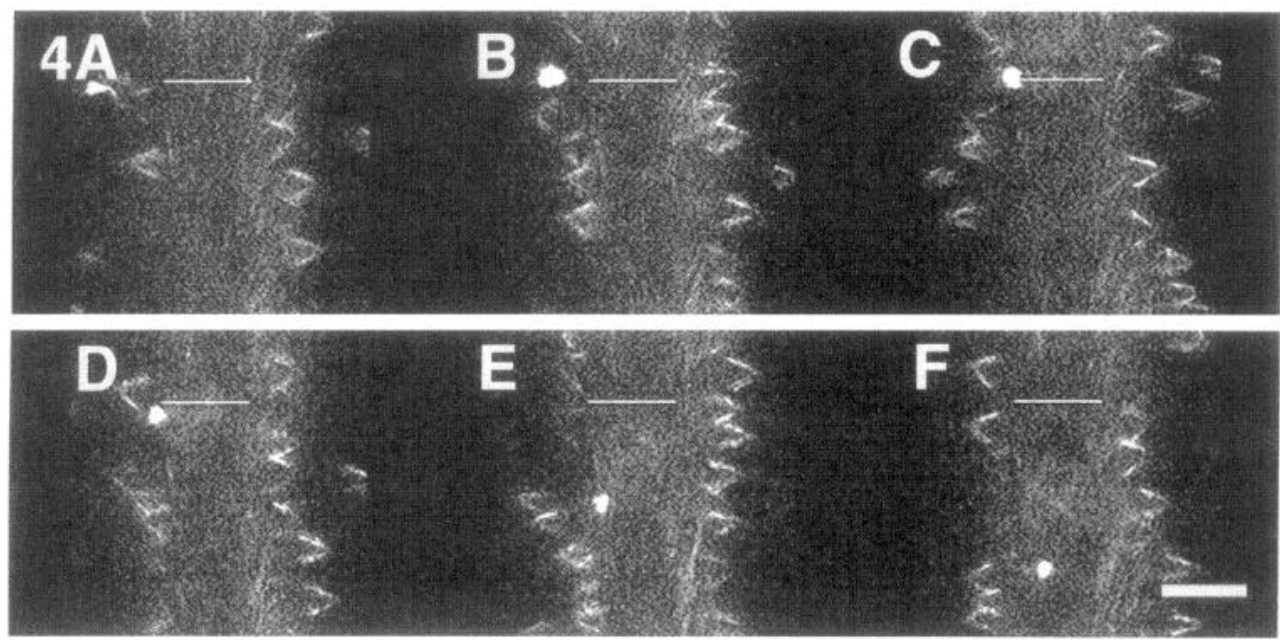

Figure 4. A confocal microscopy time series of an in vitro Mytilus edulis gill filament. A 1- $\mu \mathrm{m}$ fluorescent particle (bright spot under the letter A) interacted with a cirrus and was moved toward, but not onto, the frontal surface of the filament $(\mathrm{A}-\mathrm{C})$. On the next contact with a cirrus, the particle was moved into the frontal surface water current and transported rapidly (D-F). The reference line marks the initial location of the particle in all of the images. The elapsed time of the series was $125 \mathrm{~ms}$. Bar $=10 \mu \mathrm{m}$. 

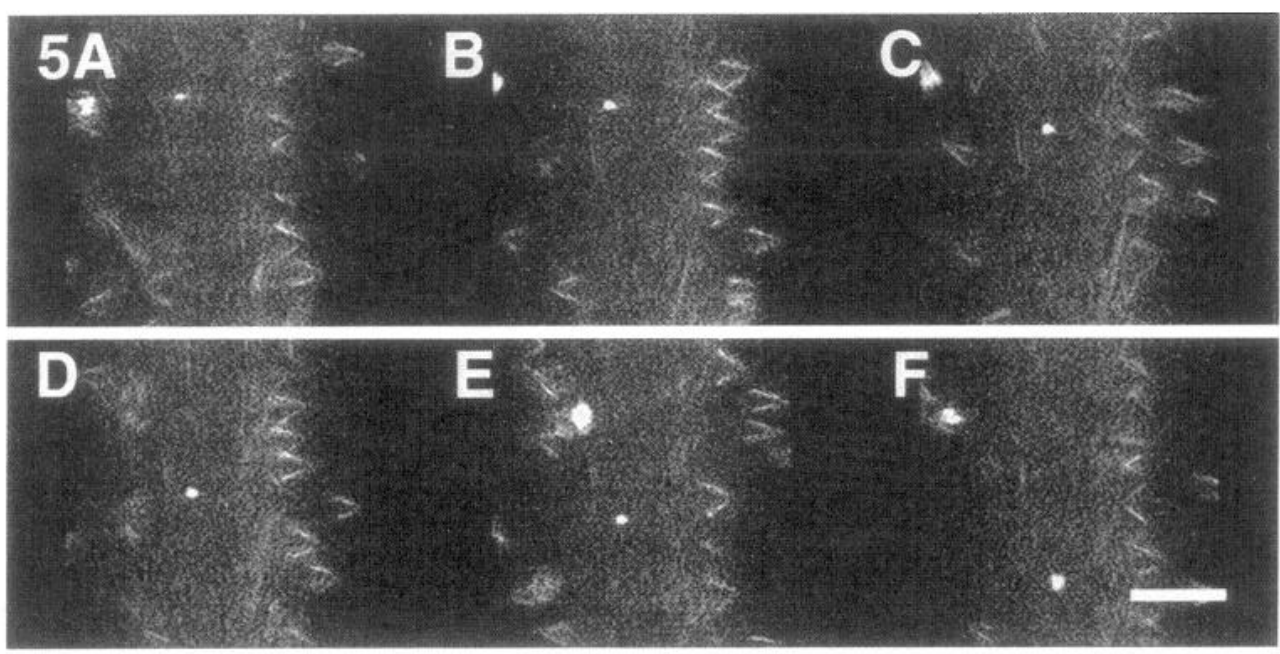

Figure 5. A confocal microscopy time series of an in vitro Mytilus edulis gill filament. A fluorescent particle moved rapidly down the center of the filament (A-F) in $125 \mathrm{~ms}$. A second particle was associated with a cirrus (A; upper left) whose ciliary tips were partially out of the plane of focus. As the cirrus continued to move back toward the extended position in the left interfilament space, the particle was drawn back with the cirrus (B-C) until it moved out of the plane of focus in D. It reappeared in E-F as the cirrus moved into its flexed position over the frontal surface of the filament. Bar $=10 \mu \mathrm{m}$.

onto the frontal surface during the power stroke of a cirrus, we could not determine whether the interaction was direct or if water acted as a mechanical coupler between the cirrus and particle (Riisgård et al., 1996). However, the close interaction (herein defined as within a few tenths of $\mu \mathrm{m}$ ) of the beating cirrus with the particle is responsible for the movement of many particles to the frontal surface of the filament where particles subsequently move in the frontal water flow. Under the experimental conditions described here for $M$. edulis, the particles can be moved to the frontal
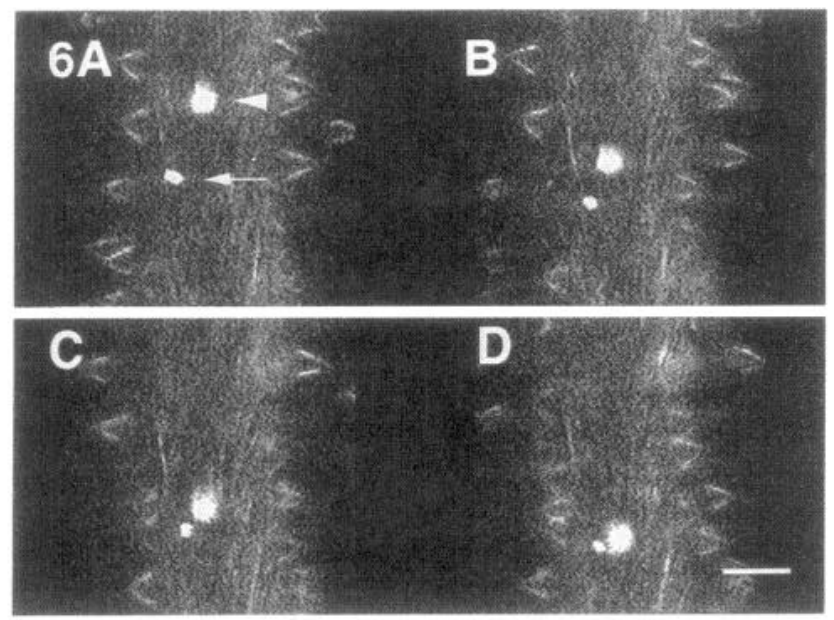

Figure 6. A confocal microscopy time series $(25 \mathrm{~ms}$ between each image) of an in vitro Mytilus edulis gill filament showing that transport of particles along a filament can occur at different rates. In these images two particles moved along the frontal surface of the filament. The larger particle (arrowhead) moved at $750 \mu \mathrm{m} \mathrm{s}^{-1}$. while the velocity of the smaller particle (arrow) was $350 \mu \mathrm{m} \mathrm{s}^{-1}$. Bar $=10 \mu \mathrm{m}$. surface of the filaments even when no mucus is visible or onto visible mucus rafts that are observed to be moving along the frontal surface (Beninger et al., 1997). In both cases, transport of particles along the frontal surface averaged about $307 \mu \mathrm{m} \mathrm{s}^{-1}$, and was similar to previously reported rates (Jones et al., 1990; Ward et al., 1991, 1993; Nielsen et al., 1993).

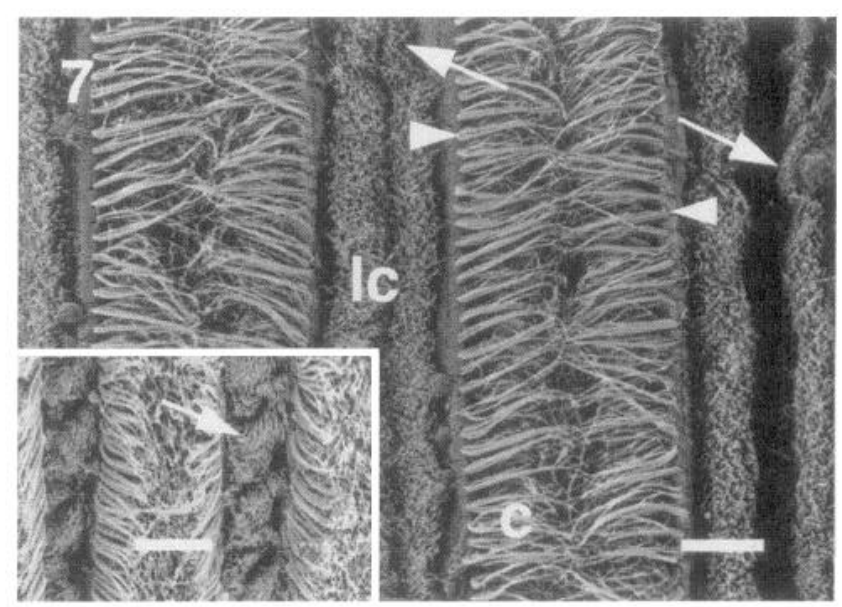

Figure 7. A scanning electron micrograph of two filaments from a Mytilus edulis gill treated with $10^{-3} M$ serotonin. The space between these fixed filaments was larger than that observed in Figure $1(20 \mu \mathrm{m}$, versus the $15 \mu \mathrm{m})$. Visible in the enlarged interfilament space are the tips of the underlying lateral cilia (lc), whose origins from two adjacent filaments are easily discernible. The arrows indicate areas where the lateral cilia were fixed in the various phases of beat associated with the metachronal wave form (inset, lower magnification). The cirri (c) in these preparations are stopped over the frontal surface of the filament, occluding much of the frontal surface. Each cirrus is composed of pairs (arrowheads) of cirral plates containing $18-26$ cilia. Bar $=10 \mu \mathrm{m}$, inset bar $=20 \mu \mathrm{m}$. 


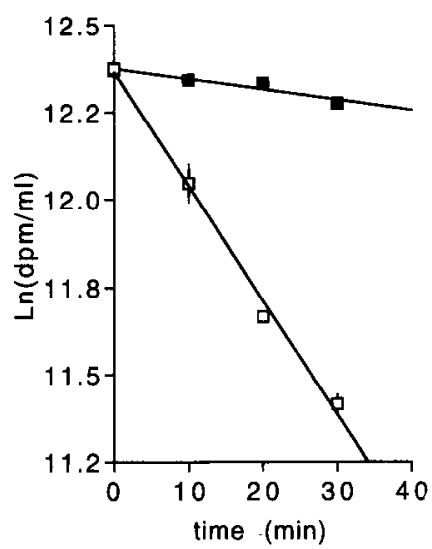

Figure 8. Time-dependent removal of Escherichia coli from $5^{\circ} \mathrm{C}$ seawater by Mytilus edulis controls (open square) or treated with $10^{-3} \mathrm{M}$ serotonin (filled square). Each point represents the mean \pm SEM for 3 animals (SEM smaller than the symbols are not visible). The regression equation for the control mussels was: $Y=-0.033 X+12.365, r^{2}=0.994$, and treated: $\mathrm{Y}=-0.003 \mathrm{X}+12.376, \mathrm{r}^{2}=0.908$.

The role of these ciliary organelles in particle capture associated with suspension feeding has been controversial. Early workers including Atkins (1937) and Dral (1967) suggested that cirri were important as "mechanical" filters or traps that moved particles onto the frontal surface of the gill filament for subsequent transport. Support for this view is gained from the differential particle capture in bivalve species with cirri of different sizes (Owen and McCrae, 1976; Møhlenberg and Riisgård, 1978; Jørgensen et al., 1984). McHenery and Birkbeck (1985) suggested that Escherichia coli were captured more effectively by marine bivalves with larger cirri than by those with small or no latero-frontal cirri. A similar relationship between cirral size and particle capture has been reported for several freshwater bivalves (Silverman et al., 1995, 1997; Tankersley, 1996).

The observations of particle/cirral interactions described here extend the observations of Riisgărd et al., (1996). These earlier observations were based on traditional light microscopic lenses immersed in water (theoretical maximum resolution approximately $0.5 \mu \mathrm{m}$ ) to observe particle interaction with cirri in isolated $M$. edulis gills. Their isolated gill preparation contained $10^{-7} M$ serotonin to stimulate ciliary activity and were positioned to maintain the normal interfilament gap $(40 \mu \mathrm{m})$ at the level of the lateral ciliated cells. The greater resolution of CLSM provides more structural detail, and the high image capture speed $(<$ $1 \mu \mathrm{s})$ and recording speed (120 frames $\left.\mathrm{s}^{-1}\right)$ allow better visualization of particle interaction with the cirri. The confocal images indicate that the cirrus was responsible for the movement of $1 \mu \mathrm{m}$ particles onto the frontal surface of the gill filament. The similarity of the results between these two studies, where different methods were used, supports the accuracy of information gained from both studies.

While observation of cirral/particle interactions with the CLSM provides evidence for the role of cirri in the particle capture process, it does not provide the information under the normal water flow conditions expected in vivo. Ward and his colleagues have provided endoscopic videos (1998a, b) that permit observation of dye streams and the motion of relatively large particles $(7 \mu \mathrm{m})$ as they move within the pallial cavity toward the gill of a living $M$. edulis. Ward $e t$ al. (1998a) indicate that particles approach the gill at a low angle (less than $30^{\circ}$ ) and are either captured by the filament or bounce until they are subsequently captured. Observing these endoscopic videos, it appears that there is a nonrandom location of the particles interacting at or near the edge of the filament. These near-field interactions probably represent interception by the cirri, rather than particle capture by the frontal water flow (Ward et al., 1998a). The endoscopic observations are valuable to describe flows and gross movements of particle approach to the filaments. The variable resolution and relatively low magnification limit the observations that are necessary to identify precise mechanism(s) of interaction between filament organelles and individual particles. Thus, it is not possible to determine the distances separating particles from the structures on the gill filament. Despite the particular limitations of both the confocal and the endoscopic observational approaches, the data obtained from each appear to be complementary and suggest the importance of both cirral interaction (near-field) and water flow (far-field) for particle capture in this species. These data also are complementary to those obtained by Riisgård and his colleagues (1996, 2000) demonstrating cirral interaction with particles in various isolated preparations and also in young undisturbed mussels.

Although most reports indicate that isolated $M$. edulis gills must be stimulated by $10^{-7} M$ serotonin to maintain ciliary activities, we have found that sections of isolated gills commonly have beating cilia. We selected preparations where latero-frontal cirri, and frontal and lateral cilia were all beating. The beat frequency of the cirri $(8 \mathrm{~Hz})$ and the patterns of motion were similar to the $4-9 \mathrm{~Hz}$ observed by Dral (1967) in young mussels in vivo. He noted that intact $M$. edulis displayed a diverse repertoire of ciliary activity, including spontaneous arrest. While Dral (1967) highlights a beat cycle that places adjacent cirri offset by $1 / 2$ beat cycle, he points out that there are many other relationships between adjacent cirri that would not be detected with the methods used. The data presented in this study also are consistent with the recent in vivo observations of Riisgarrd and Larsen (2000) and with the modeling done by Riisgard and colleagues based on isolated filament preparations (Nielsen et al., 1993; Riisgård et al., 1996). Indeed, the observations made here are consistent with the calculations of Silvester and Sleigh (1984) who suggest that laterofrontal cirri can act as "sieves," although perhaps more water moves around rather than through the cirrus (Riisgård et al., 1996).

The finding of an $83 \%$ reduction in particle capture in Mytilus edulis after serotonin is used to block cirral move- 
ment (Ward et al., 1998a) also is consistent with the previous results of Jørgensen (1983), who showed that cirral movement was critical to particle capture. The reduction in particle capture efficiency after serotonin administration has been ascribed to a breakdown in cirral-generated water currents (Ward et al., 1998a). However, the data of the present study provide an alternate explanation. The observations of the present study confirm that the cirri of treated specimens are arrested in the flexed position (Jørgensen, 1975, 1983), eliminating direct cirri particle interaction while the frontal and lateral cilia continue to beat. Furthermore, the positions of the arrested cirri physically block particles from approaching the frontal surface following serotonin treatment. Bacterial clearance was reduced $90 \%$ under these conditions. On occasion we have noted that cirral beating may be spontaneously arrested. Dral (1967) also noted that ciliary organelles on in vivo mussel gills would spontaneously become motionless. Fluorescent particles moving in the frontal water current were observed to "fall" occasionally or be deflected from the frontal surface (Nielsen et al., 1993; unpub. obs. in D. polymorpha). Thus, cirral activity is important for both particle capture and, perhaps, keeping particles entrained in the frontal water current.

In addition to the cirral arrest, serotonin also caused gill musculature to relax in preparations (Jørgensen, 1983; Medler and Silverman, 1997), which can increase the interfilament distance. In modeling particle-capture mechanisms, the dimensions of gill structures (ostial size, interfilament space, filament size, cirral size), rate of ciliary beat, and ambient hydrostatic pressure are all critical components (Silvester and Sleigh, 1984; Famme et al., 1986; Grünbaum et al., 1998). Riisgård and Larsen (2000) point out that the calculations based on in vitro gill dimensions must at least match intact clearance values, microscopic measurements on intact tissues, and particle transport rates, if such calculations are to accurately predict mechanism. Many of these components are neither fixed nor necessarily uniform across a gill at any particular time (Medler and Silverman, 1997; Medler et al., 1999).

We cannot determine whether the particle-delivery mechanism involves direct particle contact with the cirri. However, at the observed proximity of the particle with the cirrus $(<1 \mu \mathrm{m})$, the question of 'hydromechanical' versus 'mechanical' becomes irrelevant, as any intervening water is essentially a mechanical coupler. Evidence for this reasoning comes from particles that were not successfully moved to the frontal surface on the first cirral interaction. Many of these particles were drawn back with the cirrus as it moved toward the extended position (Figs. 4, 5). These particles appeared to reside within the space $(2.2-2.8 \mu \mathrm{m})$ between the free tips of the two ciliary plates making up the cirrus. The particle ( $1 \mu \mathrm{m}$ in diameter) could be physically wedged between the plates, moving within the water being drawn back by the cirrus during its extension, or by cohesive contact with the plates. The amount of water that might be moving with the cirri is small according to the model of Riisgård et al. (1996). In addition, their model indicates that particles can make contact with the cirral plate. The mechanism for particle capture is close interaction with the cirrus, and at low Reynolds numbers, hydromechanical and mechanical are essentially the same, and consistent with the confocal observations made in this study.

Both the eulamellibranch, Dreissena polymorpha and the filibranch Mytilus edulis species have homorhabdic gills and complex cirri, and capture small particles in the near-field when cirral movements cause particles to be deflected onto the frontal surface. The cirri stop the particles and then transfer them to the frontal flow (Riisgård et al., 1996; Beninger et al., 1997; Riisgård and Larsen, 2000; this study). The environment of the transfer is non-steady state, low Reynolds number (Grünbaum et al., 1998). Predicting exact particle movements without actually observing them is difficult (Shimeta and Jumars, 1991). Far-field observations are possible using endoscopy that situate particle capture in intact specimens near the latero-frontal cirri (Ward $e t$ al., 1998a). Near-field interactions are visible with CLSM (Silverman et al., 1996; this study). These observations, together with microscopic observations on single filaments or isolated gills (Nielsen et al., 1993; Riisgård et al., 1996), and studies using in vivo preparations (Dral, 1967; Riisgård and Larsen, 2000) all demonstrate the importance of cirri and their direct interaction with particles during the capture process.

\section{Acknowledgments}

This project was supported by Louisiana State University Sea Grant Program NA46RG0096 R/ZMM-5. We thank Julie Cherry, Ron Bouchard, Paul Bruce, and Chris Thibodaux for technical assistance. This research was aided by the M. D. Socolofsky Microscopy Facility. Additional video images may be viewed at http://www.biology.lsu.edu/research.

\section{Literature Cited}

Atkins, D. 1937. On the ciliary mechanisms and interrelationships of lamellibranchs. II. Sorting devices on the gills. Q. J. Microsc. Sci. 79: 339-373.

Beninger, P. G., S. St-Jean, Y. Poussart, and J. E. Ward. 1993. Gill function and mucocyte distribution in Placopecten magellanicus and Mytilus edulis (Mollusca: Bivalvia): the role of mucus in particle transport. Mar. Ecol. Prog. Ser. 98: 275-282.

Beninger, P. G., J. W. Lynn, T. H. Dietz, and H. Silverman. 1997. Mucociliary transport in living tissue: the two-layer model confirmed in the mussel Mytilus edulis L. Biol. Bull. 193: 4-7.

Chambers, E. L., and J. de Armendi. 1979. Membrane potential, action potential and activation potential of eggs of the sea urchin, Lytechinus variegatus. Exp. Cell Res. 122: 203-218.

Dral, A. D. G. 1967. The movements of the latero-frontal cilia and the 
mechanism of particle retention in the mussel (Mytilus edulis L.). Neth. J. Sea Res. 3: 391-422.

Famme, P., H. U. Rlisgård, and C. B. Jørgensen. 1986. On direct measurement of pumping rates in the mussel Mytilus edulis. Mar. Biol. 92: 323-327.

Grünbaum, D., D. Eyre, and A. Fogelson. 1998. Functional geometry of ciliated tentacular arrays in active suspension feeders. J. Exp. Biol. 201: 2575-2589.

Jones, H. D., O. G. Richards, and S. Hutchinson. 1990. The role of ctenidial abfrontal cilia in water pumping in Mytilus edulis L. J. Exp. Mar. Biol. Ecol. 143: 15-26.

Jørgensen, C. B. 1975. On gill function in the mussel Mytilus edulis L. Ophelia 13: 187-232.

Jørgensen, C. B. 1983. Fluid mechanical aspects of suspension feeding. Mar. Ecol. Prog. Ser. 11: 89-103.

Jørgensen, C. B. 1990. Bivalve Filter Feeding: Hydrodynamics, Bioenergetics, Physiology and Ecology. Olsen and Olsen Press, Fredensborg, Denmark.

Jørgensen, C. B., T. Kiørboe, F. Møhlenberg, and H. U. Riisgård. 1984. Ciliary and mucus-net filter feeding, with special reference to fluid mechanical characteristics. Mar. Ecol. Prog. Ser. 15: 283-292.

McHenery, J. G., and T. H. Birkbeck. 1985. Uptake and processing of cultured microorganisms by bivalves. J. Exp. Mar. Biol. Ecol. 90: 145-163.

Medler, S., and H. Silverman. 1997. Functional organization of intrinsic gill muscles in zebra mussels, Dreissena polymorpha (Mollusca: Bivalvia), and response to transmitters in vitro. Invertebr. Biol. 116: 200-212.

Medler, S., C. C. Thompson, T. H. Dietz, and H. Silverman. 1999. Ionic effects on intrinsic gill muscles in the freshwater bivalve, Dreissena polymorpha. Comp. Biochem. Physiol. A. 122: 163-172.

Møhlenberg, F., and $\mathbf{H}$. U. Riisgård. 1978. Efficiency of particle retention in 13 species of suspension feeding bivalves. Ophelia 17: 239-246.

Moore, H. J. 1971. The structure of the latero-frontal cirri on the gills of certain lamellibranch molluscs and their role in suspension feeding. Mar. Biol. 11: 23-27.

Nielsen, N. F., P. S. Larsen, H. U. Riisgård, C. B. Jørgensen. 1993. Fluid motion and particle retention in the gill of Mytilus edulis: video recordings and numerical modelling. Mar. Biol. 116: 61-71.

Owen, G. 1974. Studies on the gill of Mytilus edulis: the eu-laterofrontal cirri. Proc. R. Soc. Lond. B. 187: 83-91.

Owen, G., and J. M. McCrae. 1976. Further studies on the latero-frontal tracts of bivalves. Proc. R. Soc. Lond. B. 194: 527-544.

Riisgard, H. U. 1988. Efficiency of particle retention and filtration rate in 6 species of Northeast American bivalves. Mar. Ecol. Prog. Ser. 45: 217-223.

Riisgård, H. U., and P. S. Larsen. 2000. A comment on experimental techniques for studying particle capture in filter-feeding bivalves. Limnol. Oceanogr. (In press).

Riisgård, H. U., P. S. Larsen, and N. F. Nielsen. 1996. Particle capture in the mussel Mytilus edulis: the role of latero-frontal cirri. Mar. Biol. 127: 259-266.

Shimeta, J., and P. A. Jumars. 1991. Physical mechanisms and rates of particle capture by suspension-feeders. Oceanogr. Mar. Biol. Annu. Rev. 29: 191-257.

Silverman, H., E. C. Achberger, J. W. Lynn, and T. H. Dietz. 1995. Filtration and utilization of laboratory-cultured bacteria by Dreissena polymorpha, Corbicula fluminea, and Carunculina texasensis. Biol. Bull. 189: 308-319.

Silverman, H., J. W. Lynn, and T. H. Dietz. 1996. Particle capture by the gills of Dreissena polymorpha: structure and function of laterofrontal cirri. Biol. Bull. 191: 42-54.

Silverman, H., S. J. Nichols, J. S. Cherry, E. Achberger, J. W. Lynn, and T. H. Dietz. 1997. Clearance of laboratory-cultured bacteria by freshwater bivalves: differences between lentic and lotic unionids. Can. J. Zool. 75: 1857-1866.

Silverman, H., J. W. Lynn, and T. H. Dietz. 2000. In vitro studies of particle capture and transport in suspension-feeding bivalves. Limnol. Oceanogr. (In press).

Silvester, N. R., and M. A. Sleigh. 1984. Hydrodynamic aspects of particle capture by Mytilus. J. Mar. Biol. Assoc. UK 64: 859-879.

Sprung, M., and U. Rose. 1988. Influence of food size and food quantity on the feeding of the mussel Dreissena polymorpha. Oecologia 77: 526-532.

Tankersley, R. A. 1996. Multipurpose gills: effect of larval brooding on the feeding physiology of freshwater unionid mussels. Invertebr. Biol. 115: 243-255.

Ten Winkel, E. H., and C. Davids. 1982. Food selection by Dreissena polymorpha Pallas (Mollusca: Bivalvia). Freshwater Biol. 12: 553558.

Ward, J. E., P. G. Beninger, B. A. MacDonald, and R. J. Thompson. 1991. Direct observations of feeding structures and mechanisms in bivalve molluscs using endoscopic examination and video image analysis. Mar. Biol. 111: 287-291.

Ward, J. E., B. A. MacDonald, R. J. Thompson, and P. G. Beninger. 1993. Mechanisms of suspension feeding in bivalves: resolution of current controversies by means of endoscopy. Limnol. Oceanogr. 38: 265-272.

Ward, J. E., L. P. Sanford, R. I. E. Newell, and B. A. MacDonald. 1998a. An new explanation of particle capture in suspension-feeding bivalve molluscs. Limnol. Oceanogr. 43: 741-752.

Ward, J. E., J. S. Levinton, S. E. Shumway, and T. Cucci. $1998 \mathrm{~b}$. Particle sorting in bivalves: in vivo determination of the pallial organs of selection. Mar. Biol. 131: 283-292. 